\title{
PODER E RELIGIÃO NA CONTEMPORANEIDADE: UM DIÁLOGO ENTRE RATZINGER, HABERMAS E AGAMBEN1
}

\author{
POWER AND RELIGION IN MODERN SOCIETY: \\ a Dialogue Between Ratzinger, Habermas, and Agamben.
}

GLAuco BARSALINI ${ }^{(*)}$

\begin{abstract}
RESUMO
O debate travado entre o filósofo Jürgen Habermas e o cardeal Joseph Ratzinger publicado, no Brasil, com o nome Dialética da Secularização: sobre razão e religião, é inspirador. Enquanto, em uma posição liberal, Habermas defende o império da razão prática como âncora do pluralismo entre religiosos e entre não religiosos e religiosos, Ratzinger propugna pela anterioridade do criador a qualquer projeto humano, e pela existência de um ethos ocidental que correlacione razão com religião. Longe das perspectivas liberal e conservadora, Giorgio Agamben pensa uma nova forma de relacionamento humano. Reflete sobre a possibilidade da inoperosidade ou da despotencialização/desativação da política violenta imposta pelo Estado e pelo mercado. Em O Reino e a Glória denuncia a centralidade do elemento religioso nas formas de vida política, jurídica e material do mundo ocidental e, em Profanações, propõe a subversão da vinculação da religião com as formas institucionais de poder. Neste artigo coloca-se, lado a lado, o pensamento liberal do formulador da teoria do agir comunicativo, o conservador - de Bento XVI - e, por fim, o anárquico, do jusfilósofo italiano, tendo por objeto o problema da religião na sua conexão com as instituições políticas, jurídicas e econômicas.
\end{abstract}

Palavras-Chave: Secularização. Religião. Poder. Política. Linguagem.

\section{ABSTRACT}

The debate between philosopher Jürgen Habermas and Cardinal Joseph Ratzinger - entitled The Dialectics of Secularization: On Reason and Religion - is inspiring. While Habermas liberally defends practical reason as the anchor of pluralism among religious people and among religious and non-religious people, Ratzinger advocates the creator's precedence to any human project and the existence of a Western Ethos that correlates reason with religion. Far from liberal and conservative perspectives, Giorgio Agamben considers a new type of human relationship. He reflects on the possibility of the inoperosity or disempowerment/decommissioning of the violent policts imposed by the State and by the market. In The Kingdom and the Glory, Agamben criticizes the centrality of the religious element in the political, legal, and material aspects of life in the Western world, and, in

(*)Professor Pesquisador do Programa de Pós-Graduação em Ciências da Religião (Mestrado) e da Faculdade de Ciências Sociais da PUC-Campinas. Inscrito na linha de pesquisa "Fenômeno Religioso: Dimensões Epistemológicas", é membro do Grupo de Pesquisa "Ética, Política e Religião: Questões de Fundamentação". Doutor em Filosofia pela UNICAMP. Email: glaucob@puc-campinas.edu.br

${ }^{1} \mathrm{O}$ presente artigo resulta, em boa medida, da articulação entre duas comunicações realizadas em 2015 e conexas entre si: a primeira, no $28^{\circ}$. Congresso Internacional da SOTER e, a segunda, no V Congresso da ANPTECRE, ambas com previsão de publicação em Anais. Anote-se que a participação na ANPTECRE contou com o Auxílio da Fundação de Amparo à Pesquisa do Estado de São Paulo (FAPESP) [processo no. 2015/13477-5, Fundação de Amparo à Pesquisa do Estado de São Paulo (FAPESP)]. 
Profanations, he proposes the subversion of associating religion with institutional forms of power. This study compares the liberal point of view of the formulator of the theory of communicative action, the conservative thought of Pope Benedict XVI, and the anarchic thinking of the Italian, legal philosopher, considering the issue of religion and its relationship with political, legal and economic institutions.

KEYWORDS: Secularization. Religion. Power. Policy. Language.

\section{INTRODUÇãO}

Dois são os aspectos do poder criativo: a autoridade (auctoritas) e o poder prático (potestas).Ambos são humanos e se ligam ao transcendente. O conceito de autoridade se identifica diretamente com o que está além do mundo material; a ela atribui-se a designação de poder espiritual. O poder prático, por sua vez, tem identidade com o mundo dos fatos -é qualificado como o poder material, o que intervém diretamente na vida de cada um dos entes viventes ou não viventes a ele submetidos.

Fala-se, aqui, de dois corpos: o espiritual e o material. É no interior deste universo que a tradição católica ocidental tem concebido os poderes político e jurídico (ou o poder político-jurídico, se entendermos que ambos estão intrinsecamente ligados um ao outro). É também aí, na identificação de que há dois poderes - um espiritual e, outro, material - que a tradição racionalista do ocidente tem pensado a política e o direito.

Entre os séculos XIX e XX, a secularização impôs severas restrições ao modelo de Estado religioso. Em confronto direto com o organicismo católico, o materialismo propôs a superação de Deus e a criação de um centro de poder laico. Por muito tempo entendeu-se que essa nova forma de exercer soberania e direito prescindia (ou deveria prescindir) absolutamente da religião (ou das religiões) e que, portanto, o exercício religioso e das religiosidades não deveria extrapolar o âmbito privado de modo a não se tornar pauta de debates públicos, quanto menos de políticas públicas.

Tem-se discutido, cada vez com maior força, a relação entre Estado e religião, espaço público e religião. Não há, aliás, como se esquivar dessa questão, dado que os fenômenos contemporâneos associados a religiões, dentre os quais os rotulados como fundamentalistas - no mundo oriental como no ocidental - ocupam mais e mais espaço no cenário político, econômico e social de boa parte dos países.

Neste contexto se inserem reflexões de pensadores como Jürgen Habermas, Joseph Ratzinger e Giorgio Agamben que, apontando para sentidos diferentes entre si, ajudam a pensar as relações entre religião, razão e política na contemporaneidade. 
No texto que se segue, procuraremos estabelecer um diálogo entre essas três personalidades, tomando como referência o problema da relação entre a religião e o poder na atualidade.

1 RAZÃO, MORAL, RELIGIÃO E PODER NO MUNDO ATUAL

Em 1935, o teólogo Erick Peterson cravou na obra $O$ monoteísmo como problema político: uma contribuição à história da Teologia Política no Império Romano a frase lapidar: "le roi règne, mais il ne gouverne pas"3.

Resultado de acurada percepção sobre a realidade do poder político moderno, essa locução nos parece bastante atual, talvez mais presente do que nunca.

Retomando a expressão, Giorgio Agamben (2012) perscruta as contradições entre a autoridade e o poder na sua concretude, a saber, o governo. Em alusão a Robert W. Dyson, o italiano resgata o conceito da existência de duas espadas na Igreja, a espiritual e a material. A primeira corresponde à auctoritas e, a segunda, à potestas. Sem a espada espiritual, a material ignora o caminho a ser percorrido. Sem a espada material, a espiritual não se realiza. Nessa perspectiva, a Igreja personifica a autoridade - e tudo aquilo que a ela se liga e que se realiza no mundo das coisas, expressa, de certo modo, o seu reinado. $\mathrm{O}$ poder que se realiza no mundo material - e que tem caráter funcional - corresponde àquilo que os gregos chamavam de oikonomia (administração da casa) ou, em expressão atual, management4 .

O ponto nodal da discussão entre auctoritas e potestas está no entendimento de que, embora necessariamente ligadas uma à outra, pode ocorrer, entre ambas, a subversão da natural complementariedade mútua de modo que o governo, justamente por não ser efetivado pelo rei, pode deste se apartar. Emerge, aí, a ideia de que o administrador, se representante do criador, tem passe livre para decidir pelo próprio

\footnotetext{
3[“O rei reina, mas não governa”.]

4Em conferência realizada em 10 de novembro de 2005, no Centro de Cultura Contemporânea de Barcelona (publicada, posteriormente, no Brasil), Agamben afirma: "Oikonomia (...) significa em grego administração da casa. Oikos é mais amplo que o nosso termo casa porque também compreende a empresa familiar e as relações entre o proprietário e os escravos. No tratado aristotélico ou pseudoaristotélico sobre a economia lê-se que a tekne oikonomike se distingue da política como a casa, o oikos, se distingue da cidade, polis. A diferença se confirma na política, em que o político e o rei, que pertencem à esfera da polis, são contrapostos qualitativamente ao oikonomos e ao despotas, que se referem à esfera da casa e da família (...) a oikonomia se apresenta como uma organização funcional, uma atividade de gestão que não está vinculada a outras regras mais que ao ordenado funcionamento da casa ou da empresa em questão. $\mathrm{O}$ termo moderno que talvez corresponda melhor à esfera de sentido do grego oikonomia é management." (AGAMBEN, 2014, p. 28. 29)
} 
criador, o que pode implicar, no limite, em uma conduta alheia aos princípios mais fundamentais estabelecidos por aquele que o originou.

No debate realizado com o filósofo Jürgen Habermas em 19 de janeiro de 2004, o então cardeal Joseph Ratzinger clarificou sua posição em defesa da anterioridade do criador a qualquer projeto humano. Ao falar do poder e do direito, afirmou:

Fazer com que o poder seja submetido ao direito, para assim ordenar seu uso sensato, é concretamente a função da política. O que deve prevalecer não é o direito do mais forte, e sim a força do direito. Poder a serviço da ordem e do direito é o pólo oposto à violência entendida como um poder que age sem direito e contra o direito. Por isso, é importante para toda e qualquer sociedade superar a desconfiança em relação ao direito e à ordem, porque só assim é possível evitar o arbítrio e viver a liberdade de forma compartilhada por todos. A liberdade sem direito é anarquia que destrói a liberdade. A desconfiança e a revolta contra o direito ganham força quando o próprio direito já não parece ser a expressão de uma justiça a serviço de todos, e sim produto de um arbítrio, isto é, de uma usurpação do direito praticada por aqueles que detêm o poder. (...) É possível falar em justiça ou em direito em geral, quando uma maioria, por mais absoluta que seja, aflige, por exemplo, uma minoria religiosa ou uma raça por meio de leis opressoras? Vê-se, portanto, que o princípio da maioria continua deixando sem solução a questão dos fundamentos éticos do direito: será que não existe aquilo que nunca poderá vir a ser direito, isto é, que será sempre injusto? E não existirá, inversamente, também aquilo que, por sua essência, há de ser sempre direito, sendo anterior a qualquer decisão da maioria e devendo ser respeitado por ela? (RATZINGER apud SCHÜLLER, 2007, p. 65/68).

O cardeal que, no ano seguinte a essa conferência se tornaria papa, defende o direito natural. Filia-se, pois, a uma tradição medieval que, seriamente comprometida com a ideia de estabilidade social, desautoriza qualquer proposta que conceba a possibilidade de as pessoas agirem contra esse direito. Para Bento XVI não há direito que tenha o direito de suplantar o anterior direito natural: não há, portanto, razão que possa sobrevir, legitimamente, à anterior razão. O estabelecimento de uma nova razão significaria um gigantesco risco à ordem e, consequentemente, à paz social. Nesse caminho, a razão dos homens deve ser tocada pela religião, ou melhor, deve estar envolvida por esta, superando, conforme Hübner, a "obcecação histórica de que a fé já não teria nada a dizer ao ser humano” (RATZINGER apud SCHÜLLER, 2007, p. 89)5.

Ao mencionar os perigos reais que o avanço da ciência criou, como o desenvolvimento da bomba atômica, o papa aduz:

5Florian Schüller organizou e prefaciou, no livro intitulado Dialética da Secularização: sobre razão e religião, os textos referentes aodebate travado entre o filósofo Jürgen Habermas e o então cardeal Joseph Ratzinger na noite de 19 de janeiro de 2004, promovido em Munique, pela Academia Católica da Baviera. As citações feitas por Ratzinger (caso do trecho que antecede esta nota) ou as transcrições de trechos de Ratzinger ou de Habermas, constantes no referido livro, serão referenciadas, aqui, como é devido, em Schüller, organizador da obra em questão. 
[...] Por isso se faz necessário que a razão também seja levada a reconhecer seus limites e a aprender com as grandes tradições religiosas da humanidade. Quando ela passa a se emancipar completamente, deixando de lado a disposição de aprender e de se correlacionar, ela se torna destruidora. (...) Nesse sentido, eu falaria da necessidade de uma correlacionalidade entre razão e fé, entre razão e religião. Ambas são chamadas a se purificarem e curarem mutuamente, e é necessário que reconheçam o fato de que uma precisa da outra. (RATZINGER apud SCHÜLLER, 2007, p. 88/89)

Bento XVI, na mesma trilha, aliás, de seu antecessor, João Paulo II, reatualiza a defesa da fé e da moral das religiões, propugnando pela interdependência entre ciência e religião, de modo que possam aprender, uma com a outra. Significa dizer que não é possível mais às religiões fecharem-se para o conhecimento científico como, por outro lado, vai em mau caminho a ciência que abandona os princípios do direito natural, pavimentando a banalização da vida humana. Afinal, que tipo de autoridade pode ter uma ciência que não preserva o sentido sagrado da vida?

Tributário do direito racional, Jürgen Habermas também concebe um projeto de integração entre religião e razão para a contemporaneidade, tempo histórico que ele chama de pós-secular. Na senda de Hegel, o teórico hodierno afirma:

[...] as grandes religiões constituem parte integrante da própria história da razão. Já que o pensamento pós-metafísico não poderia chegar a uma compreensão adequada de si mesmo caso não incluísse na própria genealogia as tradições metafísicas e religiosas. De acordo com tal premissa, seria irracional colocar de lado essas tradições "fortes" por considerá-las um resíduo arcaico. Tal "desleixo" significaria a impossibilidade de qualquer tentativa de explicação do nexo interno que liga essas tradições às formas modernas de pensamento. Até o presente, as tradições religiosas conseguiram articular a consciência daquilo que falta. Elas mantêm viva a sensibilidade para o que lhes falhou. Elas preservam na memória dimensões de nosso convívio pessoal e social, nas quais os progressos da racionalização social e cultural provocaram danos irreparáveis. Que razão as impediria de continuar mantendo potenciais semânticos cifrados capazes de desenvolver força inspiradora - depois de vertidas em verdades profanas e discursos fundamentadores? (HABERMAS, 2007, pp. 13/14)

Na perspectiva habermasiana, os Estados democráticos atuais devem proteger a possibilidade da livre expressão individual e coletiva de conhecimentos e ideias, de interesses econômicos, políticos e sociais, de desejos individuais ou coletivos, em sua condição subjetiva ou objetiva; bem como de religiosidades e de manifestações religiosas.

Nesse sentido, o Estado secularizado deve manter-se ideologicamente neutro, não cabendo a ele promover qualquer tipo de "generalização política de uma visão de 
mundo secularizada"(HABERMAS apud SchüllER, 2007, p. 57).Encontra-se, aí, a defesa da disponibilização do espaço público (ou político) ao convívio entre fiéis de diferentes religiões, bem como entre religiosos e não religiosos. A atuação das instituições religiosas e o exercício das religiosidades no espaço público são, não somente legítimosquanto, mais que isso, desejáveis. Há um certo magnetismo entre a laicidade do Estado e qualquer forma de expressão religiosa ou de religiosidade como, também, em relação ao seu antônimo: o ateísmo. Nas palavras do filósofo:

A compreensão da tolerância das sociedades pluralistas, dotadas de uma constituição liberal, exige não somente que os crentes tenham, no seu trato com não-crentes e crentes de outras denominações, a compreensão razoável de que eles têm de contar com a permanência de um dissenso. Portanto ela exige, no âmbito de uma cultura política liberal, a mesma compreensão dos não-crentes no trato com crentes. [...]

A neutralidade em termos de visões de mundo, que impregna o poder do Estado, o qual garante iguais liberdades éticas para cada cidadão, não se coaduna com a generalização política de uma visão de mundo secularista. Cidadãos secularizados não podem, à proporção que se apresentam no seu papel de cidadãos do Estado, negar que haja, em princípio, um potencial de racionalidade embutido nas cosmovisões religiosas, nem contestar o direito dos concidadãos religiosos a dar, em uma linguagem religiosa, contribuições para discussões políticas. Uma cultura política liberal pode, inclusive, manter a expectativa de que os cidadãos secularizados participarão dos esforços destinados à tradução - para uma linguagem publicamente acessível - das contribuições relevantes, contidas na linguagem religiosa. (HABERMAS, 2007, p. 128). ${ }^{6}$

Por detrás da defesa do direito à expressão está a teoria da comunicação. Habermas (2007) vê a linguagem como mediação da comunhão entre os seres humanos. Para ele, a comunicação linguística coloca-se como "camada de uma comunhão sem a qual não podemos existir como indivíduos", pois "nós nos encontramos preliminarmente no elemento da linguagem" de modo que "somente os que falam podem calar. Nós podemos nos isolar porque somos ligados, naturalmente, com outros".

Ao entender que o espaço público deve se abrir integralmente às expressões religiosas e não religiosas, em mútuo e equilibrado diálogo e, mais, ao compreender, como transcrito, que os "potenciais semânticos cifrados" próprios às religiões, são

\footnotetext{
${ }^{6}$ Um ano antes da publicação de Zwischen Naturalismus und Religion. Philosophische Aufsätze (2005 - traduzido, no Brasil, por Entre Naturalismo e Religião: Estudos Filosóficos, 2007), no debate que empreendeu com Joseph Ratzinger, Habermas traz conclusões sobre a necessidade do entendimento da neutralidade ideológica do Estado em benefício da pluralidade e da democracia religiosa e secular.
} 
"capazes de desenvolver força inspiradora" ou, ainda, que "as tradições religiosas conseguiram articular a consciência daquilo que falta", mantendo "viva a sensibilidade" para o que "falhou"ao pensamento pós-metafísico, Habermas (2007) parece propor, portanto, algo muito próximo ao que defende Bento XVI. Atente-se, no entanto, para que, embora a proposta do teórico da ação comunicativa venha a convergir para o mesmo fim que a do papa, o da correlação entre religiões e razão, os pontos de partida de ambos são bastante distintos.

O Sumo Pontífice concebe que a criatura não deve, em hipótese alguma, negligenciar o criador, ou seja, que a cultura secular não deve olvidar a religião. $O$ segundo corpo (cultura secular) é aquele que realiza, mas não pode fazê-lo de forma justa sem ouvir o primeiro corpo (o religioso), pois é este que conserva a autoridade, enquanto aquele corresponde à ação. Ocorre que, aqui, a ação não deve pensar que detém o próprio espírito consigo, pois sua autoridade é secundária, porque é criatura e não fonte de criação. Surge, então, o perigo do engano. O direito racional pode se esquecer de que há um anterior direito natural e, com isso, colocar todo o projeto de Deus em risco, condenando a humanidade ao seu próprio fim.

O filósofo, por sua vez, é herdeiro do racionalismo. Seu pensamento se circunscreve na esfera do poder criado. Deve-se lembrar que, desde o advento da modernidade, concebe-se que a criatura também pode criar e que, portanto, no direito racional podem-se elaborar novos direitos, os quais estão ou não de acordo com o direito natural. Habermas (2012), contudo, confia no poder edificante da razão e procura, nesta esfera, encontrar saídas para a realização da cooperação entre os seres humanos por meio do agir comunicativo. E aqui cabe tudo o que se permite em uma legítima democracia, incluindo-se o diálogo entre as religiões e a cultura secularizada, de modo a garantir-se, aos religiosos, que possam, pela linguagem própria às religiões, colaborar para os debates públicos.

Conforme se demonstrou acima, o papa, cônscio do abismo que historicamente se abriu entre as religiões e a cultura pós-metafísica, em tom de urgência, clama pela reaproximação entre as antigas e a nova tradições. Para tanto, procura atualizar a autoridade da Igreja, ao colocá-la em estreito diálogo com o management moderno. $\mathrm{O}$ filósofo alemão, com boa dose de otimismo e, confiante nas democracias atuais, vislumbra a possibilidade de pleno diálogo entre as religiões e o pensamento e agir próprios ao mundo secularizado. Crê que, pela linguagem, a potestas pode se deixar afetar pela auctoritas. Agamben, por sua vez, no diagnóstico que realiza acerca das estruturas do poder moderno e contemporâneo do ocidente coloca, no centro dos 
debates, a religião, questionando a relevância da complementariedade ou do conflito entre a auctoritas e a potestas, binômio legitimado por Bento XVI e por Habermas.

\section{Giorgio AgAmben, RELigio E O FIM DOS DisPoSitivos}

Para Agamben, os mecanismos implicados nesses conceitos redundam, na modernidadee no mundo contemporâneo, em efeitos que estão bastante distantes da paz entre os homens. Isso porque a dupla auctoritas/potestas, no jogo ambivalente em que se encontram, tem gerado, desde antanho, violência e exclusão. Em eixo bastante diferente do assumido por Bento XVI e, também, por Habermas, Agamben propõe a corrosão das bases sobre as quais se erguem as formulações de ambos, a saber: a estrutura de poder auctoritas/potestas.

A despeito de todo o aparato jurídico e político que protege o exercício das religiões e a fluidez das religiosidades, do conjunto de teses otimistas em relação à possibilidade de construção de uma democracia religiosa na contemporaneidade (a exemplo das formulações de Habermas) e, ainda, da existência de grandes redes constituídas por grupos, organizações sociais e instituições que militam pela causa da liberdade de expressão religiosa, emergem, cada vez com maior força, movimentos atuais de tipo fundamentalista7. Surgem, então, as seguintes questões: em um contexto tão propício à democracia, de onde vêm os fundamentalismos atuais? Não seriam as manifestações de tipo fundamentalista - religiosas, sociais e políticas fortes expressões de que há algo errado com a democracia atual? Bastaria, como sugerem Bento XVI e Habermas, promover-se certa aproximação entre tradições e secularização, para que chegássemos a um ethos de consenso e respeito mútuo nas relações políticas e sociais?

O esforço de muitos dos Estados por reconstruir internamente as bases da democracia, projetando-a, inclusive ideologicamente, ao nível mundial, como padrão a ser seguido, revelou-se, desde o princípio, débil. Sua fragilidade interna esteve -e está na sua própria fundação político-jurídica como, também, nasformas legaise nas práticas jurídicas que a ela sobrevieram, as quais, ao contrário de garantirem o pleno acesso de todos os habitantes de cada país aos chamados direitos fundamentais, deram conta de promover, sistematicamente, a exclusão de determinados sujeitos sociais, estabelecendo critérios diferenciadores entre os indivíduos.

\footnotetext{
${ }^{7}$ Para melhores esclarecimentos sobre as distinções entre o fundamentalismo religioso originário e as conotações que a expressão ganhou na atualidade, recomenda-se a leitura do artigo "The Fundamentals: ontem, hoje e sempre", de Breno Martins Campos.
} 
No plano internacional, o intento da democracia mostrou, também, a sua fragilidade. Enquanto se erigiam Estados que se autoproclamaram ou se autoproclamam democratas, surgiram e se mantiveram, por longos anos - ou, ainda, se mantém -, em grande parte dos continentes africano, latino-americano, asiático e europeu, regimes de exceção que se encarregaram ou se encarregam de caçar ou cercear direitos, de torturar e fazer pessoas desaparecerem, e de impedir, das mais variadas formas, a elevação dos povos que governaram ou que governam, a patamares sociais considerados satisfatórios pelas organizações internacionais de direitos humanos.

Necessário se faz entender que a exceção é a própria regra, ou seja, que a ambivalência democracia/ditadura é constitutiva do poder soberano moderno e contemporâneo. Dito de outra maneira, os Estados democráticos são, estruturalmente, na atualidade, aqueles que, no tabuleiro do imperialismo político e econômico mundial, se impõem sobre os Estados não democráticos.

Fundamental, ainda, compreender-se a lógica interna dos Estados democráticos: apesar da presença destacada do direito natural em suas constituições, nenhum deles conseguiu equacionar, verdadeiramente, o fim da exclusão humana ou, então, superar aquele que é, talvez, o maior mal da humanidade: o mecanismo mimético da punição e da expiação de seres humanos ${ }^{8}$.

Giorgio Agamben (2005) defende a tese de que, na atualidade, vivemos um estado de exceção permanente. Para o pensador italiano hodierno, a modernidade se ergueu não sobre o contrato social, mas sobrea violência (bando soberano), e a expressão acabada disso foram as experiências totalitárias vivenciadas pela humanidade no século XX. A estrutura de exclusão interna e externa, própria aos fundamentos dos Estados democráticos contemporâneos - que, para Michel Foucault (2005), resulta do preconceito, gene do biopoder, este, fonte da biopolítica - deflui, para Agamben (2004), da violência sobre a qual eles se construíram, e que os constitui. Tal violência renova o conceito antigo de sagrado, como aquilo, ou aquele, que pode ser defenestrado sem que a sua eliminação implique em pena a quem o faz. Remete-se, aqui, ao homo sacer, sujeito contemporâneo que ocupa um espaço nebuloso, zona cinzenta, indeterminada ou o campo. O homo sacer resume-se à zoé, vida desqualificada. Para Agamben, na atualidade, dada a permanência do estado de exceção,

${ }^{8}$ Remete-se, aqui, à obra $O$ bode expiatório, de René Girard. 
qualquer indivíduo pode, a todo momento, ser lançado ao campo e excluído como, também, por outro lado, incluído, ficando à mercê dos dispositivos próprios ao biopoder 9 .

A tese do filósofo italiano nos ajuda a compreender, então, os motivos do fundamentalismo religioso contemporâneo, no contexto da exceção, a qual se tornou, no mundo atual, regra. É porque vivemos em um estado de exceção permanente que vemos aparecer e se fortalecer, no ocidente, ano a ano, discursos e práticas religiosas excludentes e de coloração beligerante. O fundamentalismo e, com ele, a intolerância religiosa, não são, como afirmam aqueles que apostam na possibilidade de construção de uma real democracia por meio de conquistas legais e jurídicas junto ao Estado, um elemento estranho à regra. Constituem-se, contrariamente, como expressão da própria regra.

Assim, aqueles que vivem no Estado contemporâneo estão fadados a serem, no mínimo, observadores (nunca absolutamente incólumes ao conflito) ou, então, a se tornarem protagonistas da bipolaridade: tolerância versus intolerância, respeito versus desrespeito, busca pela paz versus busca pela guerra. $\mathrm{O}$ fato é que tal antagonismo não se dá porque o "mal" é uma distorção que escapou às previsões do "bem”, mas porque a guerra é, como a paz, regra; a exceção é, como a regra, regra.

Promovendo uma "genealogia teológica da economia", Agamben (2015) investigará o termo oikonomía. Na Grécia antiga, a expressão quer dizer "la administración del oîkos"10e, modernamente, "la gestión, el management"11. Trata-se de "práxis", "atividade prática", que se aplica à resolução de casos particulares. Agamben anota que, em dado momento, os clérigos introduziram o termo na teologia, falando, então, de uma "economia divina". Nesse sentido, oikonomía ligou-se à ideia de Trindade: Tertuliano, Hipólito e Ireneo entenderam que

en cuanto a su ser y a su sustância, Dios indudablemente es uno, pero em cambio em cuanto a su oikonomía, es decir, el modo em que administra sua casa, su vida y el mundo que há creado, es triple. Así como um buen padre puede confiarle al hijo la ejecuciónde ciertas funciones y ciertas tareas, sin perder por ello su poder y su unidad, así Dios le confia a Cristo la "economía", la administración y el gobierno de la historia de los hombres ${ }^{12}$. (AGAMBEN, 2015, p. 19)

9Para melhor compreensão do conceito de homo sacer, recomendamos a leitura da obra de Giorgio Agamben intitulada Homo Sacer: o poder soberano e a vida nua. Belo Horizonte: UFMG, 2004.

10"a administração do oîkos (casa)"

11"a gestão, o management".

${ }^{12}$ [no que diz respeito ao seu ser e substância Deus, indubitavelmente é uno mas, ao contrário, no que diz respeito à sua oikonomía, isto é, à forma como administra a própria casa, a própria vida e o mundo que criou, é trino. Assim como um bom pai pode confiar ao filho a execução de 
O fim do Estado teocrático medieval implicou na clara separação entre auctoritas e potestas. Conforme Agamben:

Poco a poco los teólogos se acostumbraron a distinguir entre um "discurso - o lógos - de la teología" y um "lógos de la economía” y la oikonomía finalmente se convirtió en el dispositivo a través del cual el dogma de la Trinidad y la idea de um gobierno providencial divino del mundo se introdujeron en la fe Cristiana. ${ }^{13}$ (AGAMBEN, 2015, p. 19)

À Igreja restou a espada da autoridade enquanto, aos Estados, a da força. Com o advento do capitalismo, surge um novo protagonista do exercício do poder trinitário: o mercado (AGAMBEN, 2012). Nessa leitura, governo e mercado são, portanto, dispositivos. Em Que é um dispositivo? Agamben resgata o conceito foucaultiano ${ }^{14} \mathrm{de}$ dispositivo e dá, a ele, novos contornos:

[...] llamaré dispositivo literalmente a cualquier cosa que de algún modo tenga la capacidad de capturar, orientar, determinar, interceptar, modelar, controlar y aseguar los gestos, las conductas, las opiniones y los discursos de los seres vivientes. Por lo tanto, no solo las prisiones, los manicommios, el Panóptico, las escuelas, la confesión, las fábricas, las disciplinas, las medidas jurídicas, etc., cuya conexión com el poder de algún modo es evidente, sino también la pluma, la escritura, la literatura, la filosofia, la agricultura, el cigarrillo, la navegación, los ordenadores, los teléfonos móviles y - por qué no - el lenguaje mismo, que quizás es el más antiguo de los dispositivos, em el que Miles y Miles de años atrás um primate - probablemente sin darse cuenta de las consecuencias a las que se exponía - tuvo la inconsciencia de dejarse capturar. ${ }^{15}$ (AGAMBEN, 2015, p. 23, 24).

certas funções e de certas tarefas, sem perder, por causa disso, o poder e a unidade, assim também Deus confia a Cristo a "economia", a administração e o governo da história dos homens.]

${ }_{13}^{13}$ [Pouco a pouco os teólogos se acostumaram a distinguir entre um "discurso - o lógos - da teologia" e um "lógos da economia", e a oikonomía finalmente se converteu no dispositivo através do qual o dogma da Trindade e a ideia de um governo providencial divino do mundo se introduziram na fé Cristã.]

14Remetendo a Foucault, Agamben escreve: Los dispositivos son, precisamente, aquello que ocupa el lugar de los universales em la estratégia foucaultiana: no solo tal o cual medida policial, tal o cual tecnolgía del poder, y tampoco uma generalidad obtenida por abstracción: más bien, como decía em la entrevista de 1977, "la red (Le réseau) que se establece entre estos elementos". (AGAMBEN, 2015, p. 16). [Os dispositivos são, exatamente, aquilo que ocupa o lugar dos universais na estratégia foucaultiana: não apenas essa ou aquela medida policial; essa ou aquela tecnologia do poder e, tampouco, uma generalidade conseguida através da abstração: mas sim, como dizia na entrevista de 1977, "a malha ( Le réseau) que se estabelece entre esses elementos".]

15[chamarei dispositivo literalmente a qualquer coisa que, de alguma forma, tenha a capacidade de capturar, orientar, determinar, interceptar, modelar, controlar, e assegurar os gestos, as condutas, as opiniões e os discursos dos seres vivos. Assim, não apenas as prisões, os manicômios, o Panóptico, as escolas, a confissão, as fábricas, as disciplinas, as medidas jurídicas, etc., cuja conexão com o poder, de algum modo, é evidente, como também a caneta, a escrita, a literatura, a filosofia, a agricultura, o cigarro, a navegação, os computadores, os telefones móveis e - por que não - a própria linguagem que, talvez, seja o mais antigo dos 
De que se fala, aqui? Do deísmo que tomou conta da política e da economia, do comportamento do homem moderno e contemporâneo e, mais, de seu próprio pensar. Ser liberal significa conceber que Deus está em todas as coisas e que, portanto, cada partícula (ou indivíduo) pode criar por si mesma o que deseja: aqui, as subjetividades não têm limites, mas a sua objetivação, por outro lado, sim. E as estacas que, em última instância, as circunscrevem, não as deixando transbordar, estão nos dispositivos que, apesar de deístas, mantêm, em si, o gene do teísmo: o Estado (o direito que o funda e o mantém) e o mercado. Mas os mourões que primeiro se apresentam à frente de cada uma das partículas estão nelas mesmas, ou nas relações que estabelecem umas com as outras (na linguagem, nos instrumentos de comunicação, nos recursos lúdicos que fazem parte de seu dia a dia, no que falam e no que pensam).

Nessa linha, podemos conceber que, atualmente, as religiões e as próprias religiosidades não escapam ao dispositivo. As religiões e muito das religiosidades do homem contemporâneo estão instrumentalizadas e continuam a necessitar do sacrifício, conferindo, por ele, a passagem do profano ao sagrado ou, da esfera humana para a divina (AGAmben, 2015). O que se propõe, então? A desativação dos dispositivos e, com isso, a profanação do que se separou pelo sacrifício (ou, pela recriação do homo sacer). Aqui, uma outra concepção de religio se faz necessária. De acordo com Benveniste, o termo foi concebido por Cícero como "uma hesitação que detém, um escrúpulo que impede, e não um sentimento que leva a uma ação, ou que incita a praticar o culto". Não se trata, pois, daquilo que "une os homens aos deuses" mas, sim, daquilo que "cuida para que se mantenham distintos" (AGAMBEN, 2007). Benveniste (1995) refere-se, ainda, à ideia apresentada por Lactâncio, segundo a qual devemos nos religar a Deus e a ele ficarmos presos pela piedade, bem como continuar a realizar a passagem do profano ao sagrado e, com isso, continuar fadados ao sacrifício - a única forma que encontramos para realizar tal passagem. Quando, enfim, abandonarmos essa dependência, não nos detendo mais na necessidade de nos religar a Deus, ou aos deuses, e assumirmos uma postura escrupulosa, respeitosa em relação a Ele (ou a eles), abriremos o caminho para a profanação do religioso, ou seja, para a possibilidade de uma real democracia religiosa. Afinal, "la profanación es el 
contradispositivo que restituye al uso común lo que el sacrifício había separado y dividido."16 (AGAMBEN, 2015, p. 29)

\section{CONSIDERAÇÕES FINAIS}

A partir da problemática poder e religião, procurou-se, neste breve artigo, estabelecer relações entre a teologia de Joseph Ratzinger e as filosofias de Jürgen Habermas e de Giorgio Agamben.

Buscou-se denunciar como as perspectivas do direito natural e do direito racional se aproximam no que concerne à moral, apesar de suas diferenças de origem. Crentes no poder do diálogo, ambas convergem para a ideia de construção do bem comum. Seu projeto é teleológico. Confiantes na possibilidade de se criarem saídas a partir da fórmula auctoritas/potestas, Bento XVI e Habermas renovam a convicção de que se pode construir o consenso do mútuo respeito, independentemente das diferenças existentes entre os sujeitos. Aqui, teologia e filosofia se articulam e, nesse sentido, linguagem e diálogo ganham centralidade no projeto de edificação de uma sociedade verdadeiramente humanizada.

Bento XVI propugna pelo reino da auctoritas - a qual se liga ao direito natural, ou divino - aquela que confere legitimidade à potestas. Opondo-se ao hedonismo e ao império da liberdade ligada ao princípio da maioria, privilegia a admiração à ação. Em texto de 1990, sentencia: "Não precisamos de uma Igreja mais humana: precisamos de uma Igreja mais divina, que será então realmente humana” (RATZINGER, 2015, p. 90).

Habermas, por seu turno, milita pela abertura da potestas à auctoritas. Acredita que, pela mediação da linguagem, o direito positivo deve abrir-se para a moral, leia-se, no contexto deste artigo, tradições religiosas.

$\mathrm{Na}$ contramão do otimismo próprio à metafísica teológica e racionalista, Agamben expõe o seu ceticismo em relação à fórmula auctoritas/potestase denuncia o círculo vicioso que ela gera: o estabelecimento do estado de exceção permanente.

A questão que, em nosso entendimento, se apresenta para Agamben, é: como sair dessa lógica? Como libertar-se do império da fórmula auctoritas/potestas? Como libertar-se, enfim, das estruturas propulsoras da violência, do estado de exceção e, na atualidade, da recriação do homo sacer?

${ }^{16}$ [a profanação é o contradispositivo que restitui ao uso comum o que o sacrifício havia separado e dividido.] 
A saída não é simples. Implica na desconstrução de padrões religiosos e de poder já há muito cristalizados, a iniciar pela superação da ideia de religião como re-ligação dos homens com Deus, muito além de certo tipo de religiosidade submetida fundamentalmente às tradicionais estruturas metafísicas do pensamento religioso.

\section{REFERÊNCIAS}

AGAMBEN, Giorgio. Homo Sacer: o poder soberano e a vida nua. Belo Horizonte: UFMG, 2004.

O reino e a glória. São Paulo: Boitempo, 2012.

. Estado de Exceção. São Paulo: Boitempo, 2005.

. A comunidade que vem. Belo Horizonte: Autêntica, 2013.

Profanações. São Paulo: Boitempo Editorial, 2007.

. ¿Qué es un dispositivo? Seguido de El amigo y de La Iglesia y El Reino.

Barcelona: Editorial Anagrama, 2015. 2015 .

O mistério do mal. São Paulo: Boitempo; Florianópolis: Editora da URSC,

. Estado de Exceção e Genealogia do Poder. Revista Brasileira de Estudos Políticos, Belo Horizonte, n. 108, p. 21-39, jan./jun. 2014. Disponível em:

http://www.pos.direito.ufmg.br/rbep/index.php/rbep/issue/current/showToc, Acesso em: 01 Jul. 2014.

Audiência Geral do Papa Bento XVI. Praça de São Bento, $4^{\mathrm{a}}$. feira, 22 de abril de 2009. Disponível em: <http://w2.vatican.va/content/benedictxvi/pt/audiences/2009/documents/hf_ben-xvi_aud_20090422.html $>$. Acesso em agosto de 2015.

BENVENISTE, Émile. O vocabulário das instituições indo-européias:Poder, Direito, Religião. Campinas: Editora da UNICAMP, 1995. Vol. 2.

CAMPOS, Breno Martins. The Fundamentals: ontem, hoje e sempre. Protestantismo em Revista, São Leopoldo, v. 30, p. 124-141, jan./abr. 2013. Disponível em: <http://periodicos.est.deu.br//index.php/nepp>. Acesso em maio de 2015.

FOUCAULT, Michel. Em defesa da sociedade. 4· ed. São Paulo: Martins Fontes, 2005 .

GIRARD, René.O bode expiatório. São Paulo: Paulus, 2004.

HABERMAS, Jürgen. Teoria do Agir Comunicativo:Sobre a crítica da razão funcionalista. São Paulo: Martins Fontes, 2012. Vol. 02.

Entre naturalismo e religião: estudos filosóficos. Rio de Janeiro: Tempo Brasileiro, 2007.

RATZINGER, J. Compreender a Igreja hoje: vocação para a comunhão. $4^{\mathrm{a}}$. ed., Petrópolis: Vozes, 2015. 
SCHÜLLER, Florian (Org.). Dialética da secularização: sobre razão e religião. Aparecida: Editora Ideias e Letras, 2007.

\section{AgRADECIMENTOS}

À Dra. Maria Sílvia Ianni Barsalini pela revisão das traduções do francês e do espanhol. Ao Prof. Dr. Oscar Mellim Filho, pela inestimável colaboração na revisão final do texto. 